\title{
Coho salmon Oncorhynchus kisutch strain differences in disease resistance and non-specific immunity, following immersion challenges with Vibrio anguillarum
}

\author{
Shannon K. Balfry ${ }^{1, *}$, Alec G. Maule ${ }^{2}$, George K. Iwama ${ }^{1}$ \\ ${ }^{1}$ Faculty of Agricultural Sciences and the AQUA-NET National Centre for Excellence, University of British Columbia, \\ 248-2357 Main Mall, Vancouver, British Columbia V6T 1Z4, Canada \\ ${ }^{2}$ Western Fisheries Research Center, Biological Resources Division, United States Geological Survey, \\ Columbia River Field Station, 5501A Cook-Underwood Road, Cook, Washington 98605, USA
}

\begin{abstract}
Two strains of freshwater-reared coho salmon Oncorhynchus kisutch were compared for differences in the activity of selected non-specific immune factors before and after lethal and nonlethal immersion challenges with the marine bacterial pathogen Vibrio anguillarum (Vang). Two disease challenge experiments were performed. The first experimental challenge resulted in no mortality; however, significant strain and challenge treatment effects were detected at Day 16 postchallenge. Strain differences in plasma lysozyme activity were found in pre-challenge samples. The second challenge experiment compared the same strains of coho salmon following immersion challenges in different doses of Vang. The fish were sampled at Days 0, 2, 7, and 18 post-challenge and mortality, plasma lysozyme, and anterior kidney phagocyte respiratory burst activity were compared. There were significant strain differences in mortality in the high dose group. The more diseaseresistant strain was found to have higher levels of plasma lysozyme and anterior kidney phagocyte respiratory burst activity. These strain differences were detected at various times in the lethal (high dose) and non-lethal challenge groups. There was a clear relationship between the enhanced survival of the more disease-resistant strain and a more sustained, elevated non-specific immune response following the experimental disease challenges. The results of this study suggest that the basis for strain differences in innate disease resistance is related to the ability of the fish to respond quickly to the initial infection and to maintain the response until the infection is quelled.
\end{abstract}

KEY WORDS: Non-specific immunity • Disease resistance • Vibrio anguillarum • Lysozyme • Phagocyte $\cdot$ Respiratory burst

Resale or republication not permitted without written consent of the publisher

\section{INTRODUCTION}

The non-specific immune system provides immediate protection against a variety of pathogens. Reports of genetic variation in the activity of many non-specific immune factors in fish (Chevassus \& Dorson 1990, Fjalestad et al. 1993) have provided strong evidence for the role of the non-specific immune system in disease resistance. However, a significant correlation

*E-mail: balfry@interchange.ubc.ca between the activity of the non-specific immune system and actual disease resistance (i.e., survival) has been difficult to establish. The ultimate goal of such research would be the identification of non-specific immune factors that could be used as selection criteria for breeding programs designed to produce fish with enhanced disease resistance.

The simplest and most practical approach to examining genetic variation is to compare different genetic strains (Price 1985). A strain can be defined as a genetically distinct population produced from either natural or artificially segregated breeding (Larkin 1972). Coho 
salmon Oncorhynchus kisutch strains in British Columbia (BC), Canada, have been found to possess significant genetic variation (Beacham et al. 1996) that may be attributed to geographic location. Comparisons of disease resistance within and between strains of coho salmon from BC have also been shown to have significant genetic variation (Withler \& Evelyn 1990, Beacham \& Evelyn 1992a,b). These studies, however, measured disease resistance as differences in mortality. Genetic variation in the activity of the non-specific immune system of these fish was not examined, and thus the mechanism(s) for the observed strain differences are not known.

The present study compared 2 strains of coho salmon from BC. The Kitimat and Quinsam River strains were chosen for the following comparison based on the results of Withler \& Evelyn (1990) and Beacham \& Evelyn (1992a) suggesting the superior disease resistance of the Kitimat strain. In this study 2 experiments were performed to compare the Kitimat and Quinsam strains of coho salmon for differences in the activity of the non-specific immune system and disease resistance before and after non-lethal and lethal disease challenges.

\section{MATERIALS AND METHODS}

Experimental fish. Eggs and milt from 9 male and 9 female adult coho salmon were collected from Fisheries and Oceans Canada (DFO) Kitimat River Hatchery located on the northern coast of BC. Eggs and milt from 7 males and 7 females were collected from the DFO Quinsam River Hatchery on the east coast of Vancouver Island, BC. The gametes were transported on ice to the DFO Rosewall Hatchery on Vancouver Island, where single 1:1 matings were performed. The resulting 16 full-sib families (9 Kitimat and 7 Quinsam) were incubated separately in baskets placed in a vertical stack incubator supplied with $10^{\circ} \mathrm{C}$ freshwater. Hatched alevins were transported in their incubation baskets to the Aquaculture Facility at the University of British Columbia, Vancouver, BC. The alevins from each family were released into separate compartments in a rearing trough and fed by hand to satiation twice daily for 1 mo. Approximately 750 fry from each of the families representing the 2 strains were combined into their respective rearing troughs. The fish were reared in dechlorinated freshwater and fed a commercial diet using automatic feeders. When the fish reached a mean weight of $3 \mathrm{~g}$, the strains were fin-clipped for strain identification (Kitimat coho had their adipose fins clipped while the Quinsam coho did not). Each strain was represented by approximately 1000 fish, which were combined and reared in communal tanks.
During this rearing period, the fish were maintained at ambient water temperatures (range 2 to $18^{\circ} \mathrm{C}$ ), exposed to a natural photoperiod, and hand fed a commercial dry diet to satiation daily.

Expt 1. When the fish reached a mean weight of $12 \mathrm{~g}$, 140 fish from each strain were randomly removed from the communal tanks and placed into three 2001 experimental tanks as follows: tanks 1 and 2 were designated Vibrio anguillarum (Vang) challenge tanks and each contained 60 fish per strain, and tank 3 was a sham challenge (control) tank containing 20 fish from each strain. There was a limited number of $12 \mathrm{~g}$ fish available at the time of the experiment, so fewer fish were used for the sham challenge because no morality was expected (unlike the Vang-challenged groups where mortality was expected). Ten fish from each strain were sampled from the communal tank on the day of the challenge (Day 0) to determine the baseline or pre-challenge values for the variable measured. Each tank was challenged separately as described in detail below. The actual challenge dose was calculated as $1.25 \times 10^{8}$ viable Vang cells $\mathrm{ml}^{-1}$. The challenged fish (Vang and sham) were randomly sampled on Days 2 and 16 post-challenge (pc). At each sample time, 6 fish per strain were removed from each tank for a total sample size of 12 for the Vang-challenged group and $\mathrm{n}=6$ for the sham-challenged group. The water temperature during the course of this challenge experiment ranged from 7 to $9^{\circ} \mathrm{C}$.

The sampled fish were killed in a lethal dose of tricaine methanesulfonate (MS222, Novartis AG, Basel), and the weights and strain (presence or absence of adipose fin) recorded. The tails were severed and blood was collected into 2 heparinized capillary tubes for hematocrit measurements. Plasma was collected from the hematocrit tubes and stored at $-70^{\circ} \mathrm{C}$ for later analysis of lysozyme activity. Drops of whole blood were smeared onto clean glass microscope slides to determine differential leukocyte ratios. Erythrocyte (RBCs) counts (Days 0 and 2 pc), and hemoglobin (Days 0 and 2 pc), plasma protein (Days 0, 2, and 16 pc), and plasma glucose (Days 0 and 2 pc) concentrations were measured as described below. Immediately after each fish was bled, the anterior kidney was aseptically removed and placed in $1 \mathrm{ml}$ sterile, chilled Leibovitz medium to measure phagocyte respiratory burst activity.

Expt 2. When the fish reached a mean weight of $25 \mathrm{~g}$, approximately 400 fish from each strain were removed from the communal tanks and randomly distributed into sixteen $100 \mathrm{l}$ tanks located at the University of British Columbia Aquaculture Disease Facility. The top row of 8 tanks each contained 22 fish per strain, and the bottom row of 8 tanks each contained 27 fish per strain. The fish were acclimated for $2 \mathrm{wk}$ before the 
challenge. The fish were divided into 4 treatment groups: Group 1, sham challenge (control); Group 2, low dose challenge; Group 3, moderate dose challenge; and Group 4, high dose challenge. Each group consisted of 4 tanks: 2 top row tanks (for monitoring mortality) and 2 bottom row tanks (for monitoring immune response). The groups (1 to 4) were challenged on different (subsequent) days, with each tank challenged separately. This schedule was necessary due to the amount of work and time required to complete the assays at each sample time. Fish from each group were randomly sampled ( $n=6$ per strain) immediately before the challenge (Day 0) and then on Days 2, 7, and 18 pc. During this experiment, water temperatures ranged from 11.2 to $11.5^{\circ} \mathrm{C}$. Fish were hand fed a commercial dry diet to satiation daily.

The sampled fish were killed with a lethal dose of MS222, and weights and strain (adipose fin presence or absence) recorded. The fish were bled from the caudal vessel using a heparinized syringe. Aliquots of the collected blood were taken to measure differential white blood cell counts, red blood cell counts and hematocrits (hematology described below). The remaining blood was transferred to a sterile tube and centrifuged, and the resulting plasma was stored at $-70^{\circ} \mathrm{C}$ for later lysozyme activity measurements. Immediately after each fish was bled, the anterior kidney was aseptically removed and placed in sterile, chilled Hank's balanced salt solution (HBSS) for the phagocyte respiratory burst activity assays.

The treatment groups were challenged (as described below) with the following doses of Vang (actual concentrations): Group 1 (control), no Vang; Group 2 (low dose), $5.35 \times 10^{3}$ cells $\mathrm{ml}^{-1}$; Group 3 (moderate dose), $7.90 \times 10^{5}$ cells ml ${ }^{-1}$; Group 4 (high dose), $1.26 \times 10^{9}$ cells $\mathrm{ml}^{-1}$. Immediately following the challenge, the fish were returned to their respective tanks.

Immersion challenge procedure. The marine fish pathogen Vang was used to challenge the coho salmon strains. The fish were reared strictly in fresh water and were therefore assumed to be immunologically naive to Vang. The presence of antibodies against Vang in the serum was examined before each challenge experiment by measuring agglutinating antibody titers (Roberson 1990).

Primary isolates (Pacific Biological Station, Nanaimo, $\mathrm{BC}$, isolate no. R20, serotype 01) of Vang were obtained from coho salmon that had died from experimental injection challenge with the pathogen. Vang was grown for $18 \mathrm{~h}$ on tryptic soy agar (TSA, supplemented with $1.5 \% \mathrm{NaCl}$ ) plates, harvested into sterile peptone-saline (P-S; $0.1 \%$ peptone and $0.85 \% \mathrm{NaCl}$ ), and homogenized with a sterile teflon-tipped homogenizer. The precise volume of the Vang suspension added to the challenge bath was based on absorbance measurements where $1 \mathrm{OD}_{540}$ was estimated to contain $10^{9}$ cells $\mathrm{ml}^{-1}$. The bacterial suspensions were kept on ice until the challenges were performed.

Challenge buckets containing 41 of P-S were prepared using water removed from the fish tanks. Tank water was used to minimize any stress that may be attributed to differences in water quality or temperature. Air lines were placed into each challenge bath, along with 2 to 3 drops of sterile Antifoam B (DowCorning Corp., Auburn, MI). Immediately before the fish were added to the challenge bath, an appropriate volume of the prepared bacterial suspension was added to provide the desired challenge dose. Lids were placed on the buckets and the fish were left undisturbed for $20 \mathrm{~min}$. After the challenge, the fish were netted out and placed into their designated tanks. Control- or sham-challenged groups were similarly challenged except for the addition of the bacterial suspension. The actual concentration of viable Vang used in the challenges was determined from serial dilutions of the $1 \mathrm{OD}_{540}$ bacterial suspension (diluted with P-S), dropped $(25 \mu \mathrm{l})$ in triplicate onto TSA (supplemented with $1.5 \% \mathrm{NaCl}$ ) plates and incubated overnight at room temperature. The next day, colonies were counted and the number of Vang cells $\mathrm{ml}^{-1}$ in the challenge bath was calculated. Following the challenges, dead fish were collected daily and frozen for later necropsy to confirm vibriosis as the cause of death. Kidney material was aseptically taken and streaked onto TSA plates. The fish was assumed to have died of vibriosis if relatively pure cultures of Gram-negative, motile, curved rod-shaped bacteria grew without producing pigments. Some contamination was occasionally present on the plates, as 1 to 2 non-Vang colonies.

Hematology. Collected blood was left at room temperature for approximately $1 \mathrm{~h}$, then at $5^{\circ} \mathrm{C}$ for $4 \mathrm{~h}$ before the plasma was collected by centrifuging the blood cells $\left(2000 \times g\right.$ at $5^{\circ} \mathrm{C}$ for 3 to $\left.4 \mathrm{~min}\right)$. Aliquots of plasma were placed into sterile tubes and frozen at $-70^{\circ} \mathrm{C}$ for later analysis of lysozyme activity. Hematocrit values were obtained from fresh blood that was collected in heparinized capillary tubes and centrifuged $(10000 \times g$ for $5 \mathrm{~min})$ in a microhematocrit centrifuge. Hematocrit values were expressed as the percentage of blood volume occupied by packed red blood cells ( $\%$ packed cell volume).

Blood smears (1 smear per fish) were stained with a modified Wright-Giemsa stain (Difquik, Dada Diagnostics P.R., Auburn, MI) according to manufacturer's instructions. Ten fields from each smear were systematically examined under oil immersion (1000× magnification), and the number of lymphocytes, thrombocytes, neutrophils, and monocytes were counted. Differential leukocyte ratios were determined by counting the 
number of RBCs in each field (approximately 50 per field), along with the number of each leukocyte type. The ratio of each leukocyte type was calculated and expressed as the number per $10^{3} \mathrm{RBCs}$. The number of each leukocyte type (number per $\mathrm{mm}^{3}$ blood) was calculated using the above ratio of leukocyte type per $10^{3}$ RBC and multiplying it by the number of RBCs. The number of RBCs was determined in Expt 2 by manual counts using a hemacytometer. In Expt 1, a minilab portable instrument (Iwama et al. 1995) was used to determine RBC counts. The minilab instrument was also used to determine hemoglobin, plasma protein, and plasma glucose concentrations.

Lysozyme activity. The lysoplate method was used to determine lysozyme activity (Osserman \& Lawlor 1966, with modifications outlined by Yousif et al. 1994). Briefly, this assay involved preparing agar plates (lysoagar) containing $0.60 \mathrm{mg} \mathrm{ml}^{-1}$ Micrococcus lysodeikticus (Sigma), 0.02 M NaCl, and 0.50\% agarose (Sigma) in phosphate buffer $(0.06 \mathrm{M}, \mathrm{pH} 6.0)$. Wells (approximately $3 \mathrm{~mm}$ diameter) were punched into the lysoagar, which had air dried. Hen egg white lysozyme standards (HEWL, Sigma) were used. The activity of the HEWL standard (under the assay conditions described) was determined using the turbidimetric method as described by the supplier of the HEWL standards with modifications by Grinde (1989). Samples were placed in triplicate onto separate plates, along with the HEWL standards, and incubated overnight in a moist chamber. The zones of clearance surrounding each well were measured and compared with the HEWL standards using regression analysis. Lysozyme activity was measured in triplicate and activity was expressed as mean $\mathrm{U} \mathrm{ml}^{-1}$ plasma.

Phagocyte respiratory burst activity. Respiratory burst activity of anterior kidney phagocytes was measured as the production of superoxide anion $\left(\mathrm{O}_{2}^{-}\right)$ (Expts 1 and 2) and hydrogen peroxide $\left(\mathrm{H}_{2} \mathrm{O}_{2}\right)$ (Expt 2). The production of $\mathrm{O}_{2}{ }^{-}$was measured using the nitroblue tetrazolium (NBT; Sigma) glass-adhered assay described by Anderson et al. (1992). Briefly, anterior kidney tissue homogenates (single cell suspensions) were dropped (approximately $50 \mathrm{\mu l}$ ) into duplicate wells on a cleaned glass slide and incubated in a moist chamber for $30 \mathrm{~min}$. Non-adhered cells were gently washed off with phosphate-buffered saline ( $\mathrm{pH} 7.4)$, leaving adherent phagocytes (monocytes, neutrophils, and macrophages). The NBT solution $(0.2 \%$ in $0.85 \%$ saline) was similarly dropped into each well, and the slide was incubated for another $30 \mathrm{~min}$. After this incubation, a coverglass was placed over the slide and the adherent cells were examined microscopically under oil immersion (1000× magnification). At least 100 cells from each well (therefore, 200 cells per sample) were counted. Those cells that appeared to have the mor- phological characteristics of monocytes, neutrophils, or macrophages and had a blue halo were counted as NBT positive (the blue halo being formazan precipitate produced by the reduction of NBT by $\mathrm{O}_{2}^{-}$). The results were expressed as phagocyte respiratory burst activity (\% cells NBT positive).

The production of $\mathrm{H}_{2} \mathrm{O}_{2}$ in the suspension of anterior kidney phagocytes was measured using the oxidation of phenol red by $\mathrm{H}_{2} \mathrm{O}_{2}$ (Secombes 1990). A preliminary time course study was carried out to determine the optimal incubation time (45 min). The cell suspension was washed twice in HBSS $\left(1000 \mathrm{rpm}\right.$ at $5^{\circ} \mathrm{C}$ for $20 \mathrm{~min}$ ), then resuspended in HBSS to a final concentration of approximately $10^{6} \mathrm{cells} \mathrm{ml}^{-1}$. One milliliter of the suspension was placed in a sterile tube along with $1 \mathrm{ml}$ of the phenol red solution $(0.02 \%$ phenol red, $0.01 \%$ horseradish peroxidase in HBSS). The suspension was incubated at room temperature with gentle rotation for $45 \mathrm{~min}$. The reaction was stopped with the addition of $100 \mu \mathrm{l} 1 \mathrm{~N} \mathrm{NaOH}$. Optical density was measured at $620 \mathrm{~nm}$ using phenol red solution and $\mathrm{NaOH}$ solution as the blank. A standard curve of absorbance readings was prepared using a known concentration of $\mathrm{H}_{2} \mathrm{O}_{2}$. Regression analysis of the standard curve allowed the calculation of $\mathrm{nmol} \mathrm{H}_{2} \mathrm{O}_{2}$ from the absorbance readings of the test samples.

Statistical analysis. Data expressed as percentages (respiratory burst activity and hematocrit) were arcsin square root transformed, the lysozyme data were log transformed, and the blood cell counts were square root transformed (Sokal \& Rohlf 1981). Student's t-tests were used to compare strains for differences in the prechallenge samples. Two-way ANOVA tests were used to analyze the post-challenge data, and to examine the effects of strain and infection, as well as interactions between strain and infection. Following the ANOVA tests, Student-Newman-Keuls multiple comparison tests were used to determine which groups were different. The mortality data were analyzed for strain differences using Chi square analysis. Statistical significance for all tests was determined, where $\mathrm{p}<0.05$.

\section{RESULTS}

\section{Expt 1}

Vibriosis-related death was not observed in any of the Vang- or sham-challenged groups. However, significant strain- and challenge treatment-related differences were detected for some of the variables. The Kitimat strain of coho salmon had significantly higher $(\mathrm{p}<0.05)$ plasma lysozyme activity at Day 0 (pre-challenge) than did the Quinsam strain (Fig. 1a). Significant post-challenge increases (compared with that at 

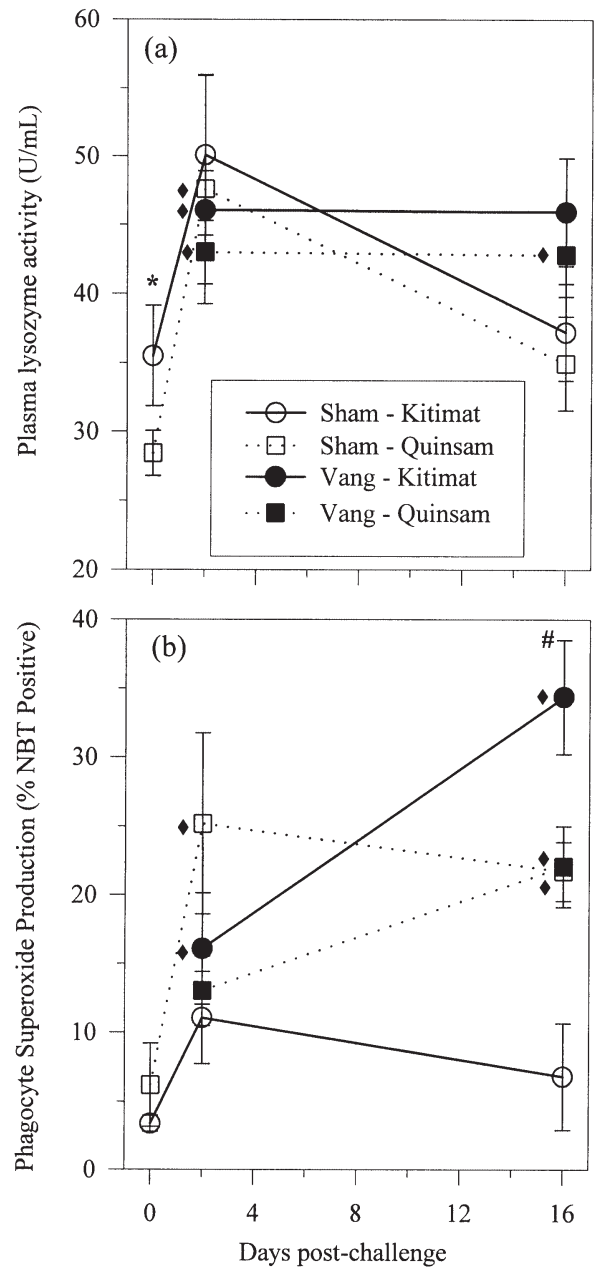

Fig. 1. Expt 1. Coho salmon Oncorhynchus kisutch strain comparison of the effect of a non-lethal immersion challenge $\left(1.25 \times 10^{8}\right.$ cells $\left.\mathrm{ml}^{-1}\right)$ with Vibrio anguillarum (Vang) on (a) mean lysozyme activity \pm SEM in plasma and (b) mean \pm SEM percentage anterior kidney phagocyte respiratory burst activity. ( * ) Significant differences between strains; (\#) significant differences between sham- and Vang-challenged treatment groups; $(\diamond)$ significant different from the Day 0 pre-challenge value. Significant difference determined where $\mathrm{p}<$ 0.05. $\mathrm{n}=10$ per strain at Day $0 ; \mathrm{n}=12$ and 6 per strain for the Vang- and sham-challenged treatment groups, respectively. NBT: nitroblue tetrazolium
Day 0) in lysozyme activity were found at Day 2 in both Vang-challenged strains and the sham-challenged Quinsam strain. Significant post-challenge differences at Day 16 were detected only in the Quinsam Vangchallenged fish. At Day 16 pc, the lysozyme activity levels in the control sham-challenged groups (Kitimat and Quinsam) tended to decrease, while the levels in the Vang-challenged groups did not.

At Day 16 pc, the Kitimat strain of coho salmon had a higher level of respiratory burst activity in the Vangchallenged group than the Quinsam strain (Fig. 1b), but this difference was not statistically significant $(\mathrm{p}>$ 0.05). Significant $(p<0.05)$ challenge treatment effects and interaction effects between strain and challenge treatment were, however, found at Day 16 pc. Phagocyte activity in the Vang-challenged groups from each strain increased significantly $(p<0.05)$ from Day 2 to Day 16 pc, while the activity was unchanged ( $p>0.05)$ in the sham-challenged groups over the same time period (Fig. 1b).

Plasma glucose concentrations were not significantly different between the 2 strains of coho salmon before the challenge (Day 0) (Table 1). However, at Day 2 pc, the concentration of plasma glucose in the Quinsam strain increased significantly in both challenge treatment groups. Plasma glucose concentrations in the Kitimat coho did not increase from Day 0 to Day 2 pc, and as such were found to be significantly lower than the Quinsam coho at Day 2 pc. The Kitimat coho salmon had higher plasma protein levels than the Quinsam coho in the Vang-challenged group (Table 1). Hemoglobin concentration, hematocrit values, differential leucocyte ratios, and RBC numbers did not show any significant strain or challenge treatment differences ( $p>0.05$ ) (data not shown).

\section{Expt 2}

There were significant strain differences in mean percentage cumulative mortality in the group receiv-

Table 1. Results from disease challenge Expt 1. Coho salmon Oncorhynchus kisutch strain comparison of mean \pm SEM plasma

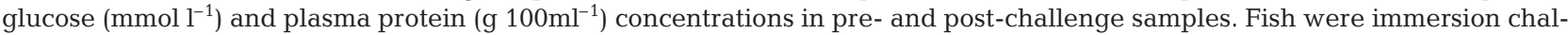
lenged with a non-lethal dose $\left(1.25 \times 10^{8}\right.$ cells ml $\left.{ }^{-1}\right)$ of Vibrio anguillarum (Vang). $\mathrm{n}=12$ and 6 of each strain for the Vang and sham-challenged groups, respectively. $n=10$ of each strain for the pre-challenge group. Different letters indicate significant differences between the means of the groups at Day 2 post-challenge (see text for description of statistical tests)

\begin{tabular}{|c|c|c|c|c|}
\hline & \multirow[t]{2}{*}{ Strain } & \multirow[t]{2}{*}{ Pre-challenge (Day 0) } & \multicolumn{2}{|c|}{ Post-challenge (Day 2) } \\
\hline & & & Sham challenge & Vang challenge \\
\hline Plasma glucose $\left(\mathrm{mmol} \mathrm{l}^{-1}\right)$ & $\begin{array}{c}\text { Kitimat } \\
\text { Quinsam }\end{array}$ & $\begin{array}{l}87.8 \pm 3.6 \\
88.4 \pm 3.7\end{array}$ & $\begin{array}{r}96.8 \pm 5.4^{\mathrm{a}} \\
181.1 \pm 3.6^{\mathrm{b}}\end{array}$ & $\begin{array}{l}106.3 \pm 6.2^{\mathrm{a}} \\
137.5 \pm 13.9^{\mathrm{c}}\end{array}$ \\
\hline 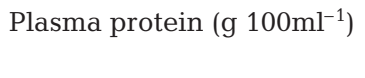 & $\begin{array}{c}\text { Kitimat } \\
\text { Quinsam }\end{array}$ & $\begin{array}{l}7.02 \pm 0.26 \\
7.22 \pm 0.34\end{array}$ & $\begin{array}{l}7.60 \pm 0.33^{\mathrm{ac}} \\
6.83 \pm 0.27^{\mathrm{bc}}\end{array}$ & $\begin{array}{l}6.77 \pm 0.27^{\mathrm{c}} \\
6.11 \pm 0.13^{\mathrm{b}}\end{array}$ \\
\hline
\end{tabular}




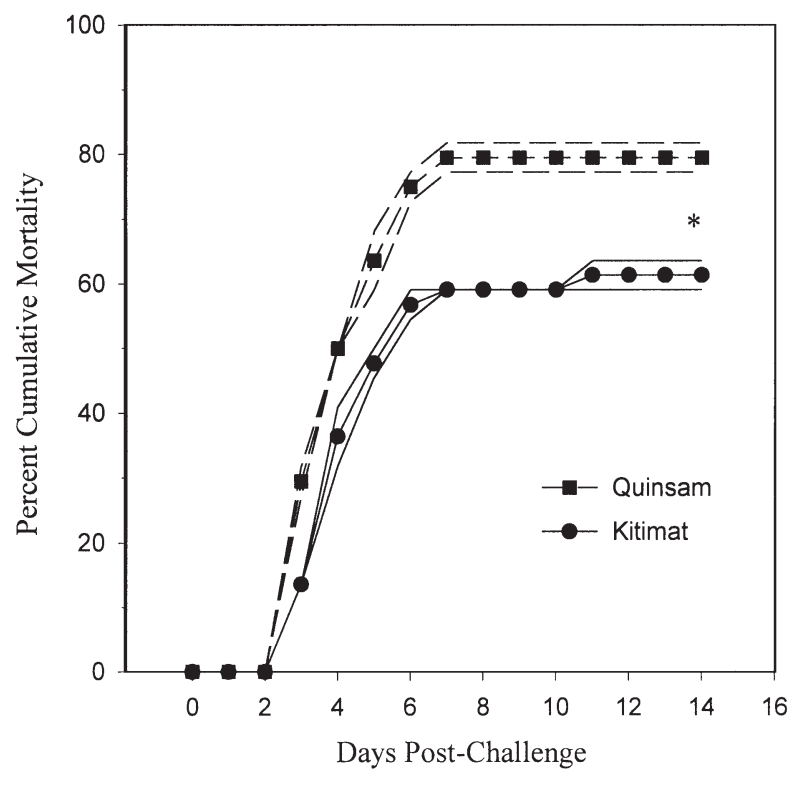

Fig. 2. Expt 2. Percentage cumulative mortality in 2 strains of coho salmon Oncorhynchus kisutch following an immersion challenge with Vibrio anguillarum (high dose group challenged with $1.26 \times 10^{9}$ viable cells $\mathrm{ml}^{-1}$ ). The solid (Kitimat) and dashed (Quinsam) lines represent the percentage cumulative mortality data obtained from the 2 replicated challenges. The center line, highlighted with the symbols, represents the mean percentage cumulative mortality. (*) Significant difference $(\mathrm{p}<0.05)$ between the 2 strains when the challenge experiment was terminated (Day 14 post-challenge)

ing the highest challenge dose, Group 4 (Fig. 2). The Kitimat coho were more disease resistant with $61.4 \%$ mortality, while the Quinsam coho had 79.5\% mortality. Deaths started on Day 3 and continued up to and during Day 11 pc. Mortality in the sham, low, and moderate challenge dose groups was 0 .

Both strains had increased lysozyme activity at Day 2 pc; however, unlike the Quinsam coho, the Kitimat coho lysozyme levels tended to remain elevated in the Vang challenge groups (Fig. 3). Lysozyme activity increased significantly from Day 0 to Day 2 in the low and high dose Vang-challenged groups (Kitimat and Quinsam strains) and the sham-challenged groups (Kitimat strain only). By Day 7 pc, the lysozyme activity in the sham-challenged groups decreased to pre-challenge (Day 0) levels. At this time, in the low and moderate challenge groups, lysozyme activity in the Kitimat coho increased (low dose) or remained elevated (moderate dose), while the Quinsam coho lysozyme activity levels were relatively unchanged (low dose) or decreased (moderate dose). In the high dose challenge groups, lysozyme activity in both strains increased at Day 7 pc, then decreased by Day 18 pc to levels still significantly greater than those at Day 0 pc. At Day 18 pc, plasma lysozyme activity in the Kitimat coho was significantly higher than in the Quinsam coho in all 3 Vang-challenged dose groups.

The Kitimat coho had significantly higher phagocyte respiratory burst activity in the moderate dose group at Days 7 and 18, and in the high dose group at Days 2 and 7 pc (Fig. 4). The Day 7 and Day 18 pc sample results from both strains in the sham, low, and moderate dose groups were significantly higher than the prechallenge (Day 0) results. Significant increases in activity over the Day 0 levels were detected by Day 2 pc for both strains in the high dose challenge group and remained elevated through to Day $18 \mathrm{pc}$.

Significant positive correlations between serum lysozyme activity and anterior kidney respiratory burst activity were detected for both strains in the low (Quinsam: $\mathrm{r}^{2}=0.41, \mathrm{p}<0.01$; Kitimat: $\left.\mathrm{r}^{2}=0.34, \mathrm{p}<0.05\right)$ and high (Quinsam: $\mathrm{r}^{2}=0.36, \mathrm{p}<0.05$; Kitimat: $\mathrm{r}^{2}=0.52$, $\mathrm{p}<$ 0.001 ) dose challenge groups. Significant correlations in the sham and moderate challenge dose groups were not detected for either strain ( $p>0.05$ ).

$\mathrm{H}_{2} \mathrm{O}_{2}$ production by the anterior kidney phagoyctes, differential leucocyte numbers, RBC numbers, and hematocrit values showed no significant strain differences or challenge dose effects (data not shown). Antibody titers against Vang were below detectable limits in both strains and experiments.

\section{DISCUSSION}

The results of this study suggest that the observed enhanced survival and innate disease resistance in the Kitimat strain of coho salmon may be related to the activity of the non-specific immune system. The more resistant Kitimat coho tended to have higher plasma lysozyme activity in the later stages of the infection and higher phagocyte $\mathrm{O}_{2}{ }^{-}$production throughout the infection (especially evident in the high dose challenge group). The rapid and continued elevation in the activity of the non-specific immune system in the more disease resistant Kitimat strain may be an important factor in destroying the pathogen and reducing the infection. These results suggest that the basis for the difference in innate disease resistance between strains may be related to the ability of the fish to respond to the initial infection and maintain a heightened level of activity until the infection is under control and no longer a health threat.

In Expt 2, the Kitimat strain had significantly greater disease resistance following the high dose vibriosis challenge. This result was not unexpected, as previous work by Withler \& Evelyn (1990) showed that, compared with Robertson Creek coho, the Kitimat coho had higher survival and a longer time to death follow- 
Fig. 3. Expt 2. Coho salmon Oncorhynchus kisutch strain comparison of mean \pm SEM plasma lysozyme activity following immersion challenges in different concentrations of Vibrio anguillarum (Vang). (a) Sham challenge, no Vang; (b) low dose challenge, $5.35 \times 10^{3}$ cells $\mathrm{ml}^{-1}$; (c) moderate dose challenge, $7.90 \times 10^{5}$ cells $\mathrm{ml}^{-1}$; (d) high dose challenge, $1.26 \times 10^{9}$ cells $\mathrm{ml}^{-1}$. (*) Significant differences $(\mathrm{p}<0.05)$ between the 2 strains at that time; $(\bullet)$ significant difference from the Day 0 (pre-challenge) level $(\mathrm{p}<0.05) . \mathrm{n}=12$ per strain

ing challenge with Renibacterium salmoninarum, the causative agent of bacterial kidney disease. In chinook salmon, the superior innate disease resistance of the Kitimat strain was also shown by Beacham \& Evelyn (1992a), who compared the disease resistance of the Kitimat, Quinsam, and Nitinat strains of chinook salmon. These researchers found that Kitimat chinook had the lowest mortality rate following separate challenges with 3 different pathogens: Vang, R. salmoninarum, and Aeromonas salmonicida.
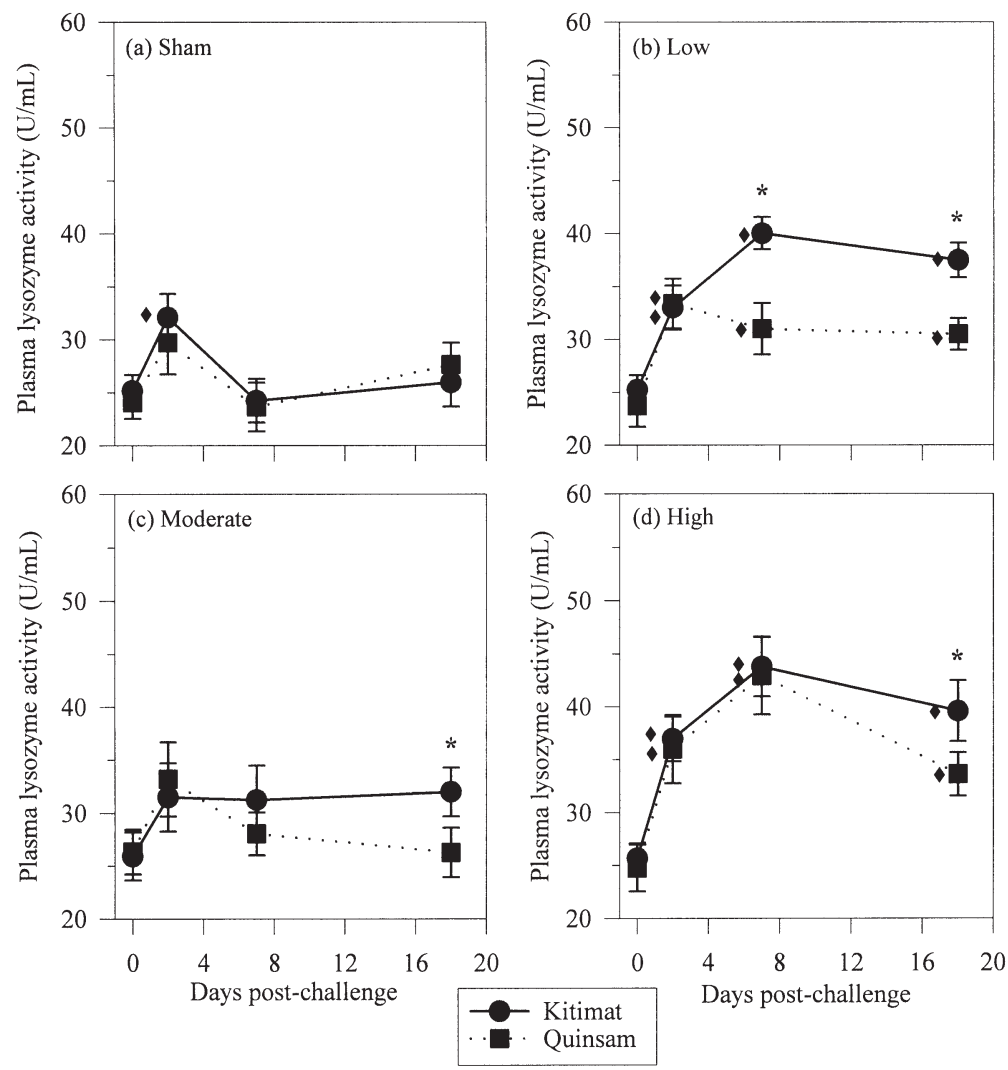
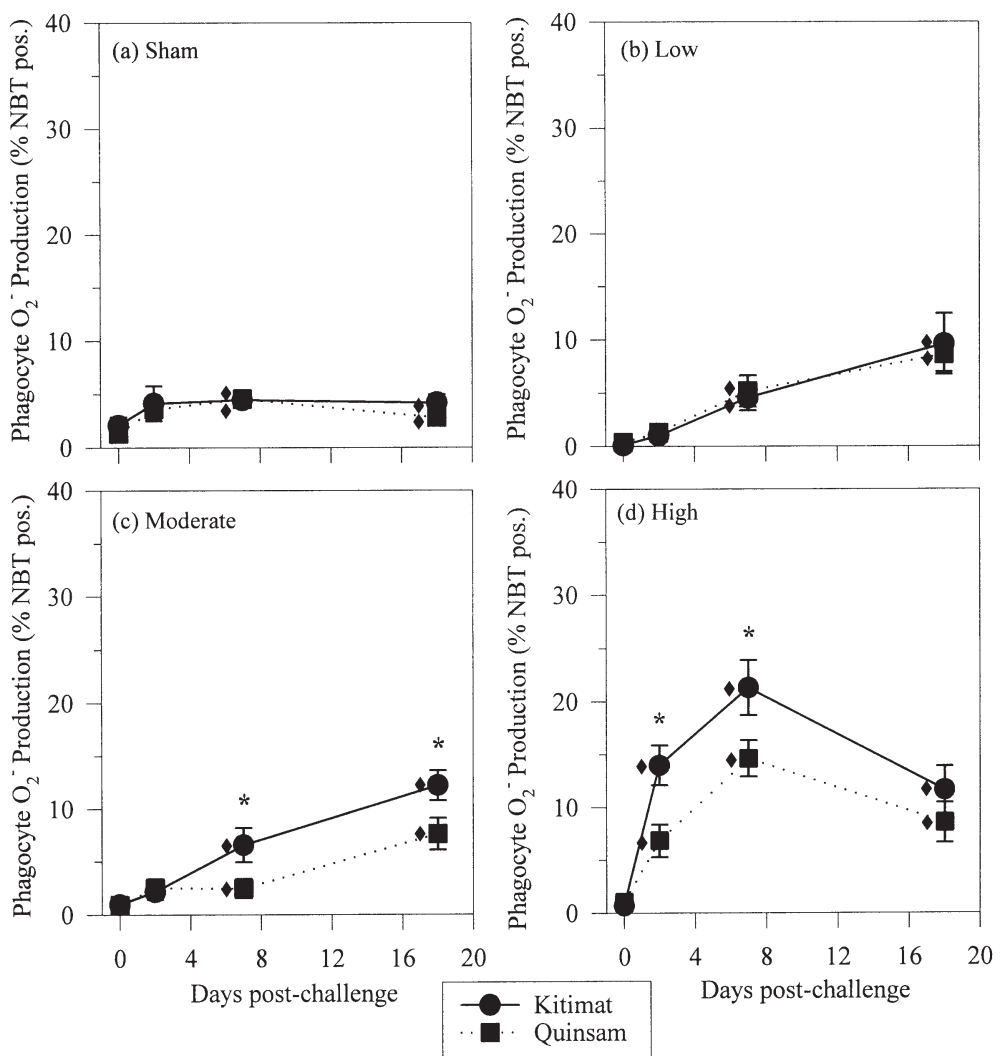

Vibriosis-related death was not observed following the challenge in Expt 1, nor in the low or moderate challenge dose groups in Expt 1. The lack of death in the moderate and low challenge dose groups in Expt 2 was likely due to the challenge dose being too low to establish an infection. Similarly, the combination of low water temperature $\left(7^{\circ} \mathrm{C}\right)$ and an insufficient challenge dose may explain the absence of post-challenge mortality in Expt 1. Groberg et al. (1983) showed that water temperatures of less than $12^{\circ} \mathrm{C}$ can suppress the in vivo growth of

Fig. 4. Coho salmon Oncorhynchus kisutch strain comparison of mean \pm SEM percentage anterior kidney phagocyte respiratory burst activity (measured using the NBT assay), following immersion challenges in different concentrations of Vibrio anguillarum (Vang). (a) Sham challenge, no Vang; (b) low dose challenge, $5.35 \times$ $10^{3}$ cells ml $^{-1}$; (c) moderate dose challenge, $7.90 \times$ $10^{5}$ cells ml ${ }^{-1}$; (d) high dose challenge, $1.26 \times 10^{9}$ cells $\mathrm{ml}^{-1}$. (*) Significant differences $(\mathrm{p}<0.05)$ between the 2 strains at that time; $(\bullet)$ significant difference from the Day 0 (pre-challenge) level $(\mathrm{p}<0.05) . \mathrm{n}=12$ fish per strain 
Vang. The results of Expt 1 indicate that the non-specific immune system did respond to the initial infection, as seen by increases in plasma lysozyme and $\mathrm{O}_{2}^{-}$production. However, because there was no death and a minimal physiological response post-challenge (as seen by the hematological measurements), it can be concluded that a diseased state (i.e., vibriosis) did not develop in the Vang-challenged coho from either strain.

The Quinsam coho strain had significantly higher plasma glucose levels at Day 2, while the Day 2 glucose concentrations in the Kitimat coho did not change from pre-challenge levels. This suggests that the Quinsam strain may be more sensitive to the stress associated with the challenge procedures. Elevations in plasma glucose are considered to be secondary metabolic effects of stress (Barton \& Iwama 1991). After a stressful event, plasma glucose concentrations have been shown to take up to $72 \mathrm{~h}$ to return to baseline (Pickering et al. 1982). Stress susceptibility has been associated with immunosuppression and a decreased ability to resist infections (Maule et al. 1989, Schreck 1996). It is therefore possible that the sensitivity of the Quinsam fish to stress may be related to the lowered survival rate of this strain (compared with the Kitimat strain) when challenged with different pathogens (Beacham \& Evelyn 1992a). Fevolden et al. (1991) found that Atlantic salmon Salmo salar from a high stress line had increased plasma glucose concentration and lysozyme activity, supporting the hypothesis that more easily stressed fish are less disease resistant. This hypothesis was further supported following later disease challenge experiments (Fevolden et al. 1993) that revealed that the high stress line were indeed less resistant to the disease furunculosis and had significantly lower non-specific immunity as measured by hemolytic activity.

The slight increases in lysozyme activity and $\mathrm{O}^{-}{ }_{2}$ production seen in the control sham-challenged group at Day 2 pc in Expt 2 were also observed in the coho salmon similarly challenged in Expt 1 . The increase may be attributed to a stress response associated with the handling and confinement of the challenge procedure. Temporary increases in serum lysozyme and phagocyte activity have been associated with mildly stressful events (Möck \& Peters 1990, Pegg et al. 1995). The stress effects, however, appear to be temporary because, by Day 7 pc, the sham-challenged groups tended to return to baseline (Day 0) levels. In contrast, in the Vang-challenged groups, lysozyme activity and $\mathrm{O}_{2}{ }^{-}$production appeared to reflect the effects of an infection (i.e., activities that were increased because a pathogen was present to stimulate the immune system). The lysozyme activity in the moderate dose challenge group were not as high as those found in the low dose challenge group. The reason for the suppressed lysozyme response in this group is not known as the $\mathrm{O}_{2}^{-}$production was increased after the challenge.

$\mathrm{H}_{2} \mathrm{O}_{2}$ production by anterior kidney phagocytes did not show any clear pattern of dose effects, and no strain differences were observed. The same phagocyte suspensions showed that respiratory burst activity was initiated with $\mathrm{O}_{2}{ }^{-}$production. It is possible that catalase or some other $\mathrm{H}_{2} \mathrm{O}_{2}$ destroying factor was present in the suspension and was somehow able to interfere with the measurements of $\mathrm{H}_{2} \mathrm{O}_{2}$ production.

Lysozyme activity has been found to increase when the immune system is stimulated, i.e., during an infection (Studnicka et al. 1986, Møyner et al. 1993). In addition, increases in fish lysozyme activity have been positively correlated with numbers of monocytes and neutrophils (Fletcher \& White 1976), which synthesize and secrete lysozyme (Murray \& Fletcher 1976). In this study, there was no significant correlation between the number of leukocytes and lysozyme activity. Although it is possible that the monocytes and neutrophils synthesized and secreted more lysozyme, the more likely source of the elevated lysozyme concentration was the macrophage. Macrophages are also capable of synthesizing and secreting large amounts of lysozyme (Gordon et al. 1974). Macrophages become activated when stimulated by foreign particulates or soluble substances. Activated macrophages produce an array of anti-microbial substances such as peroxide, $\mathrm{H}_{2} \mathrm{O}_{2}$, and lysozyme (Chung \& Secombes 1988, Secombes \& Fletcher 1992). Therefore, despite differences in the antibacterial properties of fish lysozyme against fish pathogens (e.g., Renibacterium salmoninarum is resistant to lysozyme, while Vang is susceptible), an increase in lysozyme concentration may be an important indicator of macrophage activation, and hence overall immune protection (Grinde 1989, Yousif et al. 1994). The suspension of phagocytes used for the $\mathrm{O}_{2}{ }^{-}$ and $\mathrm{H}_{2} \mathrm{O}_{2}$ production assays was assumed to consist largely of macrophages. Significant positive correlations between $\mathrm{O}_{2}^{-}$production and serum lysozyme activity in the low and high dose challenge groups suggest that the challenge infection activated the macrophages in the anterior kidney. Correlations were not significant in the control group probably because of the limited response of the immune system to the sham challenge. The fish were not exposed to the pathogen and therefore the immune system was not activated.

Significant strain differences in serum lysozyme activity and phagocyte $\mathrm{O}_{2}^{-}$production indicate that these factors may be important mechanisms underlying the enhanced disease resistance associated with the Kitimat strain. The levels of both these non-specific factors were significantly higher in the Kitimat strain in the later stages of the disease challenges. The high survival of the Kitimat strain may also be related to a 
quick non-specific immune response, because the phagocyte $\mathrm{O}_{2}{ }^{-}$production seen at Day 2 pc was significantly greater in the Kitimat strain when compared with the less resistant Quinsam strain of coho. It is therefore suggested that the basis for the differences between strains may be related to the ability of the fish to react to the initial infection, and maintain the level of response until the infection is under control.

Fevolden et al. (1992) reported that strain differences in the activity of the non-specific immune system were most evident in the early stages of the infection. A quick and effective non-specific immune system is crucial in preventing infection and therefore diseaserelated death. Significant strain differences in the activity of the non-specific immune system were observed in the present study; however, the differences were most apparent following the disease challenge. This suggests that strain differences in innate disease resistance may be related to genetic differences in the ability of the non-specific immune system to respond to a stimuli such as a pathogenic bacteria.

Strain differences in the activity of the non-specific immune system appeared to be related to innate disease resistance because lysozyme activity and phagocyte $\mathrm{O}_{2}{ }^{-}$production tended to be higher in the more disease resistant strain (Kitimat). Strain differences in survival rates and the activity of the non-specific immune system suggest a genetic basis to innate disease resistance. Other researchers have also shown genetic variation in the non-specific immune system and disease resistance (reviewed by Chevassus \& Dorson 1990, Fjalestad et al. 1993, Wiegertjes et al. 1996). The results presented here add new information about the role of the non-specific system in disease resistance and suggest possible mechanisms of resistance. The inability to detect Vang antibodies, coupled with the fact these fish were reared solely in freshwater, in a freshwater only facility, indicates that the disease resistance results observed were likely due to the non-specific immune system. Strain differences in the activity of the non-specific immune system in Nile tilapia have been shown but without differences in disease resistance (Balfry et al. 1997). This is the first reported study of strain differences in the activity of the non-specific immune system and innate disease resistance for Pacific salmon (Oncorhynchus spp.).

Acknowledgments. This work was supported by the Canadian Bacterial Diseases Network (to G.K.I.) and a Science Council of BC, GREAT Scholarship (to S.K.B.). We thank the personnel and managers of the Kitimat River, Quinsam River, and Rosewall Creek hatcheries for their assistance, and Ms E. Teng for her help in the rearing of the coho strains at the University of British Columbia. We also thank Dr L. Brown for her critical review of this manuscript and Dr T. P. T. Evelyn for his guidance throughout this project.

\section{LITERATURE CITED}

Anderson DP, Moritomo T, de Grooth R (1992) Neutrophil, glass-adherent, nitroblue tetrazolium assay gives early indication of immunization effectiveness in rainbow trout. Vet Immunol Immunopathol 30:419-429

Balfry SK, Shariff M, Iwama GK (1997) Tilapia Oreochromis niloticus strain differences in non-specific immunity following challenge with Vibrio parahaemolyticus. Dis Aquat Org 30:77-80

Barton BA, Iwama GK (1991) Physiological changes in fish from stress in aquaculture with emphasis on the response and effects of corticosteroids. Annu Rev Fish Dis 1:3-26

Beacham TD, Evelyn TPT (1992a) Population and genetic variation in resistance of chinook salmon to vibriosis, furunculosis, and bacterial kidney disease. J Aquat Anim Health 4:153-167

Beacham TD, Evelyn TPT (1992b) Genetic variation in disease resistance and growth to chinook, coho, and chum salmon with respect to vibriosis, furunculosis and bacterial kidney disease. Trans Am Fish Soc 121:456-485

Beacham TD, Miller KM, Withler RE (1996) Minisatellite DNA variation and stock identification of coho salmon. J Fish Biol 49:411-429

Chevassus B, Dorson M (1990) Genetics of resistance to disease in fishes. Aquaculture 85:83-107

Chung S, Secombes CJ (1988) Analysis of events occurring within teleost macrophages during the respiratory burst. Dev Comp Immunol 15:201-208

Fevolden SE, Refstie T, Røed KH (1991) Selection for high and low cortisol stress response in Atlantic salmon (Salmo salar) and rainbow trout (Oncorhynchus mykiss). Aquaculture 95:53-65

Fevolden SE, Refstie T, Røed KH (1992) Disease resistance in rainbow trout (Oncorhynchus mykiss) selected for stress response. Aquaculture 104:19-29

Fevolden SE, Nordmo R, Refstie T, Røed KH (1993) Disease resistance in Atlantic salmon (Salmo salar) selected for high or low responses to stress. Aquaculture 109:215-224

Fjalestad KT, Gjedrem T, Gjerde B (1993) Genetic improvement of disease resistance in fish: an overview. Aquaculture 111:65-74

Fletcher TC, White A (1976) Lysozyme activity in the plaice (Pleuronectes platessa L.). Experientia 29:1283-1285

Gordon S, Todd J, Cohn ZA (1974) In vitro synthesis and secretion of lysozyme by mononuclear phagocytes. J Exp Med 139:1228-1248

Grinde B (1989) Lysozyme from rainbow trout, Salmo gairdneri Richardson, as an antibacterial agent against fish pathogens. J Fish Dis 12:95-104

Groberg WJ, Rohovec JS, Fryer JL (1983) The effect of water temperature on infection and antibody formation induced by Vibrio anguillarum in juvenile coho salmon (Oncorhynchus kisutch). J World Maricult Soc 14:240-248

Iwama GK, Morgan JD, Barton BA (1995) Simple field methods for monitoring stress and general condition of fish. Aquacult Res 26:273-282

Larkin PA (1972) The stock concept and management of Pacific salmon. In: Simon RE, Larkin PA (eds) The stock concept in Pacific salmon. HR MacMillan Lecture in Fisheries. University of British Columbia, Vancouver, p 11-15

Maule AG, Tripp RA, Kaattari SL, Schreck CB (1989) Stress alters immune function and disease resistance in chinook salmon (Oncorhynchus tshawytscha). J Endocrinol 120: 135-142

Möck A, Peters G (1990) Lysozyme activity in rainbow trout, Oncorhynchus mykiss (Walbaum), stressed by handling, 
transport and water pollution. J Fish Biol 37:873-885

Møyner K, Røed KH, Sevatdal S, Heum M (1993) Changes in non-specific immune parameters in Atlantic salmon, Salmo salar L., induced by Aeromonas salmonicida infection. Fish Shellfish Immunol 3:253-265

Murray CK, Fletcher TC (1976) The immunohistochemical localization of lysozyme in plaice (Pleuronectes platessa L.) tissues. J Fish Biol 9:329-334

Osserman EF, Lawlor DP (1966) Serum and urinary lysozyme (Muramidase) in monocytic and monomyelocytic leukemia. J Exp Med 124:921-951

Pegg J, Balfry SK, Gordon L, Roome JR, Iwama GK (1995) Stress, immune function and disease resistance in juvenile salmonids. Bull Aquacult Assoc Can 4:28-35

Pickering AD, Pottinger TG, Christie P (1982) Recovery of the brown trout, Salmo trutta L., from acute handling stress: a time course study. J Fish Biol 20:229-244

Price DJ (1985) Genetics of susceptibility and resistance to disease in fishes. J Fish Biol 26:509-519

Roberson BB (1990) Bacterial agglutination. In: Stolen JS, Fletcher TC, Anderson DP, Roberson BS, van Muiswinkel WB (eds) Techniques in fish immulology, Vol 1. SOS Publications, Fair Haven, p 1-86

Schreck CB (1996) Immunomodulation: endogenous factors.

Editorial responsibility: David Bruno,

Aberdeen, Scotland, UK
In: Iwama GK, Nakanishi T (eds) Fish physiology, Vol 15. Academic Press, New York, p 311-338

Secombes CJ (1990) Isolation of salmonid macrophages and analysis of their killing activity. In: Stolen JS, Fletcher TC, Anderson DP, Roberson, BS, van Muiswinkel WB (eds) Techniques in fish immunology, Vol 1. SOS Publications, Fair Haven, p 137-154

Secombes CJ, Fletcher TC (1992) The role of phagocytes in the protective mechanisms of fish. Annu Rev Fish Dis 2: $53-71$

Sokal RR, Rohlf FJ (1981) Biometry. WH Freeman \& Co, San Francisco

Studnicka M, Siwicki A, Ryka B (1986) Lysozyme level in carp (Cyprinus carpio L.). Bamidgeh 38:22-25

Wiegertjes GF, Stet RJM, Parmentier HK, van Muiswinkel WB (1996) Immunogenetics of disease resistance: a comparative approach. Dev Comp Immunol 20:365-382

Withler RE, Evelyn TPT (1990) Genetic variation in resistance to bacterial kidney disease within and between two strains of coho salmon from British Columbia. Trans Am Fish Soc 119:1003-1009

Yousif AN, Albright LJ, Evelyn TPT (1994) In vitro evidence for the antibacterial role of lysozyme in salmonid eggs. Dis Aquat Org 19:15-19

Submitted: November 29, 2000; Accepted: July 17, 2001 Proofs received from author(s): October 16, 2001 